\title{
Quality of life and glaucoma
}

\author{
Qualidade de vida e glaucoma
}

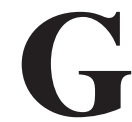

laucoma is the leading cause of irreversible blindness worldwide. ${ }^{1}$ The main and most challenging goal of treating glaucoma is to maintain the quality of life $(\mathrm{QoL})$ of patients at an acceptable cost. ${ }^{2}$

QoL is a complex and multidimensional concept that includes the health of the individual, the physical and psychological well-being, as well as a good capacity for social and cognitive performance. ${ }^{3}$ In medicine, QoL is related to several points: since the concern of the individual with the disease and its consequences, going through functional disorders caused by the disease, to the undesirable effects of the treatments. ${ }^{2}$

Individuals diagnosed with glaucoma may have their QoL impaired for many reasons: loss of visual function; difficulty in the daily routine of treatment; side effects and the treatment costs; and worries, anxiety and fear related to the diagnosis of a chronic disease that threatens the vision. ${ }^{2}$

In general, there is evidence in the literature that the more advanced glaucoma is, the worst the QoL ${ }^{4.5}$ However, this may be impaired even at early stages of the disease, as observed in the Los Angeles Latinos Eye Study (LALES). ${ }^{5}$ The loss of the visual function is the main determinant for a worse QoL in glaucoma, and may compromise the patient's daily activities such as reading, driving, walking, estimating distances and seeing objects approaching from the side. ${ }^{4}$ The psychological effects (fear of blindness and social withdrawal) of glaucoma in the individual are also not negligible and tend to increase with the disease progress. The treatment itself may have a major impact in the QoL. ${ }^{4}$

The antiglaucoma medications may influence the quality of life in different ways: the daily use of medications reminds the patient of their status as the carrier of an incurable disease; eyedrops can be expensive and difficult to be applied; local and systemic side effects, which can affect their vision and the general health; the scheme of doses, which can interfere in their daily life, leaving the patient anxious (if they are using the medication correctly). ${ }^{6}$

It has been shown that the greater the number and the prevalence of side effects of the medication, the worse the quality of life; the greater the system of droplets, the worse the quality of life ${ }^{8-9}$; the more expensive the treatment, the worse the quality and life ${ }^{8-10}$.

Few studies compared the different treatments using the patient's QoL as a result. The QoL, when used as a study outcome is the ideal way to evaluate a treatment, as this is the most important outcome measure from the point of view of the patient.

For the study of QoL as an outcome, we can use the quantitative method (use of specific instruments such as validated questionnaires) and the qualitative methods (open interviews, focus groups, etc.).

The QoL in general can be hard to be quantified. In this attempt, different instruments or methods were developed and validated. Some examples are: Visual Function Questionnaire, developed by the National Eye Institute, in the USA (NEI-VFQ); Glaucoma Symptom Scale (GSS), Glaucoma Quality of Life - 25 (GQL-25) and Symptom Impact Glaucoma Score (SIG).

A Cochrane review identified only one randomized controlled study which directly compares different types of glaucoma treatment (medication versus surgery), having as one of QoL outcomes: the Collaborative Initial Glaucoma Treatment Study (CIGTS). ${ }^{11-12}$

This study assessed 607 patients newly diagnosed with glaucoma, which were randomized for clinical treatment or trabeculectomy. The QoL was assessed by three questionnaires, which lasted approximately 48 minutes to be completed by the patients ${ }^{12}$.

The results showed that patients who underwent surgical treatment had lower QoL scores in the initial phase of treatment (mainly related to local discomfort from the surgery). This difference disappeared over time. Another important finding was that the QoL in both groups was worse soon after the diagnosis, and that the scores show a trend of improvement over time, showing that patients tend to get used to the disease and its symptoms. ${ }^{12}$

In another study to assess the QoL directly, Guedes et al. evaluated 225 patients interviewed by means of the Brazilian version of the NEI-VFQ. In this cross-sectional study, patients were divided into 3 groups, group 1 (patients exclusively under clinical treatment without ever having been under any filtering surgery); group 2 (patients operated without using any antiglaucoma medication) and group 3 (operated patients, but who needed to return to the use of antiglaucoma medication).

The groups were uniform regarding the following variables: age, sex, race, education and type of glaucoma. When controlled by the stage of glaucoma (initial, moderate and advanced), there was no difference between the scores of patients undergoing surgical treatment or those in medical treatment, except for the initial glaucoma. The results showed that patients who underwent filtering surgery in early stage of glaucoma had a lower score of QoL compared to the patients with chronic use of eyedrops. ${ }^{13}$ This difference was not observed in moderate or advanced glaucoma, and was mainly related to the psychological dimension.

Another study by the same group (Guedes et al.) assessed the QoL in patients with glaucoma under clinical treatment in use of different prostaglandins (Bimatoprost, Latanoprost and Travoprost). ${ }^{14}$ In this study, 213 patients were assessed by means of a questionnaire validated for the Brazilian population. The results showed that Travoprost had similar results of QoL to Latanoprost. Among the 3 prostaglandins, Bimatoprost was the one that showed the lowest score of $\mathrm{QoL}^{14}$, despite the fact already reported in other studies, which show that it is the one prostaglandin that further reduces intraocular pressure and is the most cost-effective drug. ${ }^{15-17}$ 
The research with qualitative methodology aims to capture the aspects related to the disease that would be very difficult to be observes in the quantitative studies of QoL. In the medical literature there are virtually no research studies with a qualitative approach which attempted to understand the beliefs and values assigned by patients with glaucoma to the type of treatment proposed by the doctor (physician or surgeon).

A study by the qualitative method was performed Vieira et al., aiming to search the different perspectives of patients about glaucoma and its treatment. ${ }^{18}$ Two focus groups were conducted, where the interviews were conducted in groups and recorded in digital media (group 1: patients exclusively under clinical treatment in advanced stages of glaucoma, and group 2: patients operated on both eyes at least 1 year before with no medication and also in advanced stage of glaucoma). ${ }^{18}$

The results showed that glaucoma raises a deep fear and concern to the patients, not only regarding the loss of vision, but also the impact of the disease and its treatment on a daily basis (falls, costs, use of eyedrops in pre-determined times, side effects, etc.).

Both groups had the same level of concern about the disease and blindness. The costs and side effects of the treatment were the most significant negative factors posed by the patients. ${ }^{18}$

The patients in the surgical group were unanimous in preferring surgery in relation to chronic use of eyedrops. Operated patients with glaucoma seem to have less impact on their daily lives, but the concern about the disease persists. ${ }^{18}$

The confidence in the doctor and in the correct indication of the treatment, be it clinical or surgical, is a major factor for more peace of mind and, consequently, a better QoL, reinforcing the need for a good doctor-patient relationship. ${ }^{18}$

The study of the impact of glaucoma and its treatment on QOL of patients is of fundamental importance because QOL is the ultimate goal of any glaucoma therapy, but it is also the most important outcome of the patient's point of view.

More studies are needed in order to deal better with the decrease of QoL in patients with glaucoma. But from now on we have to keep in mind that:

- glaucoma has a major impact in the QoL;

- the type of treatment can interfere for better or worse in the QoL;

- the doctor has a key role in maintaining and improving the QoL using the appropriate and personalized treatment, noting that one way to try to alleviate the burden of disease is to establish a good doctor-patient relationship.

Ricardo Augusto Paletta Guedes Researcher at the Federal University of Juiz de Fora (UFJF). Masters degree in Public Health (UFJF). Doctorate in Health (UFJF). Glaucoma expert at Centre Hospitalier National d'Ophthalmologie des Quinze-Vingts (University of Paris, France).

\section{References}

1. Resnikoff S, Pascolini D, Etya'ale D, Kocur I, Pararajasegaram R, Pokharel GP et al. Global data on visual impairment in the year 2002. Bull World Health Organ. 2004; 82:844-851.

2. European Glaucoma Society. Terminology and Guidelines for Glaucoma, 2nd ed. Savona, Italy: Ed Dogma; 2003.

3. Zanlonghi X, Arnould B, Bechotille A, Baudouin C, Bron A, Denis P et al. Glaucoma and quality of life. J Fr Ophthalmol. 2003 ; 26 (HS 2): 2 S39-44.

4. McKean-Cowdin R, Varma R, Wu J, Hays RD, Azen SP, Los Angeles Latino Eye Study Group. Severity of visual field loss and helathrelated quality of life. Am J Ophthalmol 2007; 143(6): 1013-23.

5. Sckalicky S, Goldberg I. Quality of life in glaucoma patients. US Ophthalmic Review. 2013; 6(1): 6-9.

6. Emerick GT. Quality of life and glaucoma medications. Do our prescriptions make a difference? Glaucoma Today. 2005; 5:38-39.

7. Nordmann JP, Auzannaeu N, Ricard S, Berdeaux G. Vision realated quality of life and topical glaucoma treatment side effects. Health Qual Life Outcomes. 2003;10:1-75.

8. Tsai J. A comprehensive perspective on patient adherence to topical glaucoma therapy. Ophthalmology 2009; 116: S30-6.

9. Hong S, Kang SY, Yoon JU, Kang U, Seong GJ, Kim CY. Drug atitude and adherence to anti-glaucoma medication. Yonsei Med J. 2010; 51(2):261-9.

10. Silva LMS, Vanconcellos JPC, Temporini ER, Costa VP, Kara-José N. Tratamento clinico do glaucoma em um hospital universitário: custo mensal e impacto na renda familiar. Arq Bras Oftalmol. 2002; 65:299-303.

11. Burr J, Azuara-Blanco A, Avenell A. Medical versus surgical interven tions for open-angle glaucoma (Cochrane Review). The Cochrane Library, Issue 4, 2007.

12. Feiner L, Piltz-Seymour JR, Collaborative Initial Glaucoma Treatment Study Group. Collaborative initial glaucoma treatment study: a summary of results to date. Curr Opin Ophthalmol. 2003; 14:106-111.

13. Paletta Guedes RA, Paletta Guedes VM, Freitas SM, Chaoubah A. Quality of Life of Medically Versus Surgically Treated Glaucoma Patients. J Glaucoma. 2012; March 7(Epub ahead of print).

14. Guedes RA, Guedes VM, Freitas SM, Chaoubah A. Quality of Life of Glaucoma under medical therapy with different prostaglandins. Clinical Ophthalmol. 2012;6:1749-53.

15. Aptel F, Cucherat M, Denis P. Efficacy and tolerability of prostaglandina analogs: a meta-analysis of randomized controlled clinical trials. J Glaucoma. 2008, 17:667-673.

16. Noecker RJ, Walt JG. Cost-effectiveness of monotherapy treatment of glaucoma and ocular hypertension with the lipid class of medications. Am J Ophthalmol. 2006; 141: S15-S21.

17. Guedes RPA, Guedes VMP, Chaoubah A. Custo-efetividade dos análogos de prostaglandinas no Brasil. Rev Bras Oftalmol. 2008; 67:281-6.

18. Vieira AA, Guedes, RA, Vieira RC, Guedes, VM. Percepção dos pacientes portadores de glaucoma sobre sua doença e os diferentes tipos de tratamento (clinico versus cirúrgico). Rev Bras Oftalmol (em submissão). 